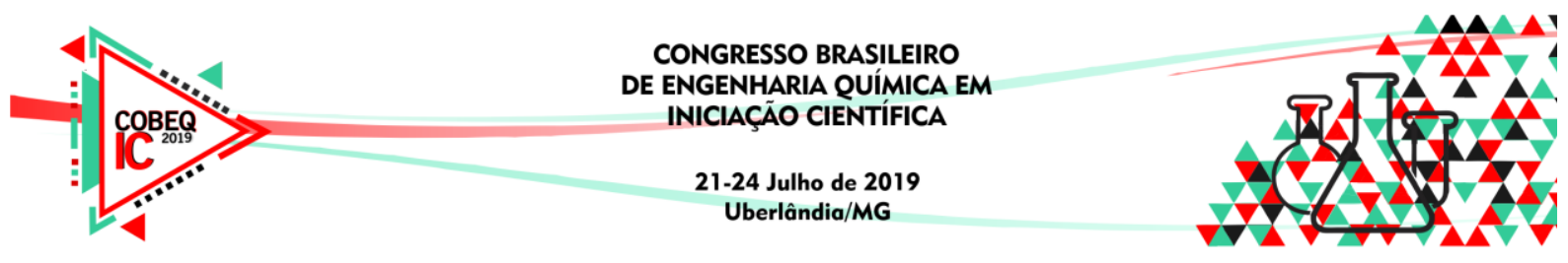

\title{
PURIFICAÇÃO DO BIODIESEL ATRAVÉS DE ADSORÇÃO UTILIZANDO AMIDO DE MILHO
}

\author{
M. B. P. O. SILVA ${ }^{1}$, E. R. R. RODRIGUES ${ }^{1,}$ G. S. S. ANDRADE ${ }^{1}$, L. LODI ${ }^{1}$ \\ ${ }^{1}$ Universidade Federal de Alfenas, Instituto de Ciência e Tecnologia \\ E-mail para contato: mariabeatrizpregnolato@gmail.com
}

\begin{abstract}
RESUMO - Neste trabalho foi avaliada a eficácia da purificação do biodiesel através do método de adsorção com amido de milho. O biodiesel foi produzido por uma reação de transesterificação metílica de óleo de soja e metanol catalisada por hidróxido de potássio. O subproduto glicerol foi retirado após decantação e o sobrenadante contendo o produto final foi submetido ao processo de purificação por adsorção. A eficiência do método de adsorção foi avaliada por meio da análise do teor de glicerol livre, que revelou remoção de $83 \%$ de glicerol quando comparado ao produto antes da adsorção. Constatou-se ainda que o processo de adsorção não afetou as características físico-químicas dos ésteres metílicos produzidos, indicando a potencialidade da aplicação de purificação a seco utilizando adsorventes de baixo custo e ampla disponibilidade.
\end{abstract}

\section{INTRODUÇÃ̃O}

Atualmente o uso de combustíveis é de extrema importância, pois eles servem de fonte para o funcionamento de motores e geradores de energia elétrica. Esses combustíveis, na maioria, são derivados do petróleo e apresentam altos fatores de poluição. Portanto, é de grande importância buscar novas alternativas para resolução dos problemas relacionados à utilização do petróleo como fonte de energia. Assim, a utilização do biodiesel surge como uma alternativa, pois o mesmo pode ser obtido por diversos processos tais como o craqueamento, a esterificação ou transesterificação.

Como a reação de transesterificação é reversível, o uso de álcool em excesso na reação é essencial para deslocar o seu equilíbrio, possibilitando assim um maior rendimento. No processo de síntese de biodiesel, a glicerina é o subproduto da reação sendo que aproximadamente $10 \% \mathrm{~m} / \mathrm{m}$ do óleo vegetal é transformado na mesma (LOPES et al. 2011). As especificações finais do biodiesel são determinadas pela Agência Nacional do Petróleo, Gás Natural e Biocombustíveis (ANP). Das várias propriedades a serem controladas, a mais significativa é a quantidade de glicerol livre, pois está diretamente relacionada com o processo de purificação que atualmente é realizado por uma lavagem úmida. Porém, devido à elevada quantidade de efluentes gerados por esse processo, são necessários novos estudos de metodologias, destacando atualmente a lavagem a seco.

Nesse contexto esse trabalho propõe avaliar a eficácia do processo de purificação do biodiesel através do método de adsorção, que consiste no transporte de massa do tipo sólido líquido na qual se aproveita os pontos positivos de certos sólidos em concentrar na sua superfície certas substâncias presentes em soluções líquidas ou gasosas, o que permite 


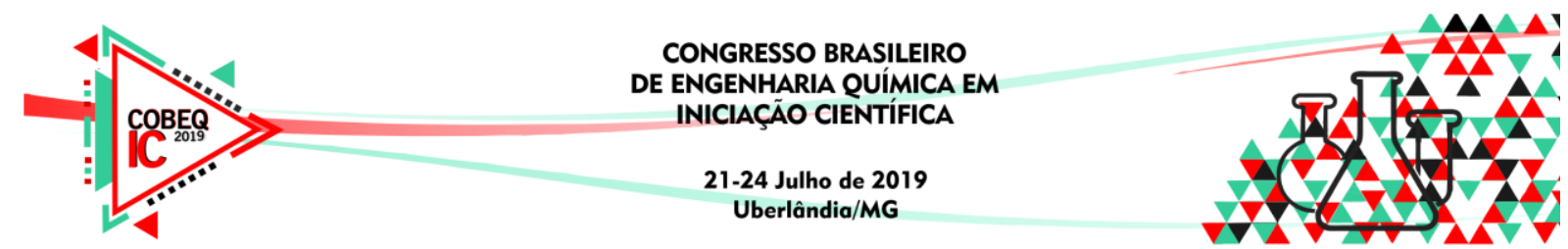

desgarrá-las dos demais componentes dessas soluções (MEHER et al. 2006). Tal método depende do sólido que será utilizado como adsorvente, pois um adsorvente adequado deve apresentar uma área específica significativa. Usualmente, o processo é reversível e uma concentração pequena no fluido irá cobrir a superfície do adsorvente até o ponto em que a pressão efetuada pela fase adsorvida é análoga à que está no fluido. O adsorvente proposto é o amido de milho, um importante material de reserva do reino vegetal cujos grânulos são feitos principalmente por dois polissacarídeos: amilose e amilopectina. Os grânulos de amido com a água causam a formação de uma suspensão viscosa chamada de gelatinização, ou seja, ocorre o colapso da ordenação granular. Nesse processo acontecem mudanças irreversíveis nas propriedades, como o inchamento dos grânulos, fazendo assim que o amido se torne com bom adsorvente (DABDOUB et al. 2006).

\section{MATERIAIS E MÉTODOS}

\subsection{Materiais}

Os materiais utilizados nas reações de transesterificação foram óleo de soja (Liza), álcool metílico (Synth) e hidróxido de potássio $(\mathrm{KOH})$ em pellets (Synth). Para o processo de adsorção foi empregado o amido de milho comercial (Maizena). Os demais reagentes empregados foram de grau analítico.

\subsection{Produção do Biodiesel}

A produção do biodiesel ocorreu em um reator batelada, através de uma reação de transesterificação. Inicialmente o $\mathrm{KOH}$ foi adicionado ao reator juntamente ao metanol e mantido sob agitação magnética até completa dissolução. Em seguida o óleo de soja foi adicionado à solução álcool/catalisador e mantidos sob agitação magnética e aquecimento a $40^{\circ} \mathrm{C}$ por 30 minutos. O meio reacional foi composto por óleo de soja e metanol em uma razão molar de 1:6 (óleo:álcool) com adição de $1 \% \mathrm{~m} / \mathrm{m}$ em relação à massa de óleo utilizada de catalisador homogêneo hidróxido de potássio. Ao final da reação de transesterificação, o produto obtido foi colocado em um funil de separação por um período de 48 horas para que houvesse a separação do biodiesel do glicerol. O glicerol bruto foi retirado pela parte de baixo do decantador e a fase leve foi submetida a purificação e análises físico-químicas.

\subsection{Processos de Purificação do biodiesel}

Purificação via úmida: Em um funil de separação foi adicionado $20 \mathrm{~mL}$ do produto obtido (biodiesel) e $20 \mathrm{ml}$ de água destilada a $40{ }^{\circ} \mathrm{C}$. O sistema foi levemente homogeneizado e deixado em repouso por 24 horas. O procedimento foi repetido por 3 vezes consecutivas.

Purificação por adsorção: Em um béquer foi adicionado $20 \mathrm{~mL}$ do produto obtido (biodiesel) e amido de milho (1\%,2\% e 3\% em relação ao volume de biodiesel). O sistema foi adicionado a um agitador magnético por um período de 30 minutos e logo após foi deixado em repouso por 24 horas até decantação completa do adsorvente. 


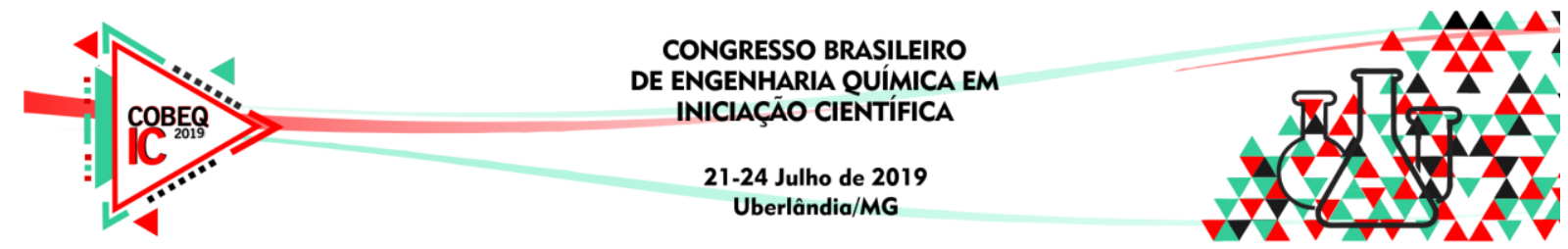

\subsection{Caracterização do biodiesel}

Viscosidade: A viscosidade dinâmica foi determinada por viscosímetro Brookfield à temperatura de $40{ }^{\circ} \mathrm{C}$. Já a viscosidade cinemática é dada pela razão entre a viscosidade dinâmica e a densidade (Lutz 2008).

Densidade: A densidade foi determinada pela técnica de picnometria a temperatura ambiente. Em primeiro lugar foi medido a massa do picnômetro vazio e em seguida colocouse a amostra no mesmo e mediu-se a massa. Por fim para efetuar sua calibração, completou-o com água e anotou-se a massa. Dessa forma, com os dados das massas das amostras e do volume do picnômetro, foi possível obter a densidade específica (Lutz 2008).

Índice de Acidez: Em um erlenmeyer de $125 \mathrm{~mL}$, foi adicionado 2 gramas da amostra, $25 \mathrm{~mL}$ da mistura de éter etílico e álcool etílico (95\%) em proporção de 2:1 em volume e 3 gotas do indicador fenolftaleína. A amostra foi titulada com uma solução de hidróxido de potássio de concentração $0,01 \mathrm{M}$ previamente padronizada até obter uma coloração rosácea permanente (Lutz 2008).

Glicerol livre - Método (AOCS): Em tubos falcon foi adicionado um grama de biodiesel adsorvido com $4 \mathrm{~mL}$ de hexano e $4 \mathrm{~mL}$ de solvente de trabalho (etanol:água,1:1 em volume). Os tubos foram submetidos à agitação em vortex por 5 minutos para promover uma melhor extração. Posteriormente as amostras foram centrifugadas por 15 minutos em 2000 rpm possibilitando assim a remoção da fase superior. Uma alíquota de $0,5 \mathrm{~mL}$ da fase inferior contendo o glicerol foi transferida para um tubo de ensaio no qual foi adicionado $1,5 \mathrm{~mL}$ de solvente de trabalho, 1,2 mL de solução de $10 \mathrm{mM}$ de metaperiodato de sódio e 1,2 da solução de $0,2 \mathrm{M}$ de acetilacetona. $\mathrm{O}$ branco foi preparado da mesma forma, porém utilizando $2 \mathrm{~mL}$ de solvente de trabalho. Logo depois as amostras foram colocadas um banho de água a $70^{\circ} \mathrm{C}$ sob agitação por 1 minuto e posteriormente resfriadas em água a $20^{\circ} \mathrm{C}$ por 2 minutos. A absorbância da mistura foi lida em um espectrofotômetro UV/Vis no comprimento de onda de $410 \mathrm{~nm}$. Os cálculos das concentrações de glicerol na amostra foram determinados com base na curva de calibração que apresentou uma correlação linear $\left(\mathrm{R}^{2}\right)$ de 0,9919 e uma equação da reta $\mathrm{y}=75,611 \mathrm{x}-0,0348$ em que y e x correspondem à absorbância e concentração de glicerol, respectivamente.

Glicerol livre - Método (ANP): A amostra de biodiesel após processo de purificação por adsorção foi submetida a análise cromatográfica realizada pelo Laboratório de Análises de Combustíveis Automotivos (LACAUT) da Universidade Federal do Paraná-UFPR, conforme método ABNT NBR 15908.

Rendimento - Método (ANP): As análises de monoacilglicerol, diacilglicerol e triacilglicerol foram realizadas pelo Laboratório de Análises de Combustíveis Automotivos (LACAUT) da Universidade Federal do Paraná-UFPR, conforme método ABNT NBR 15908. 


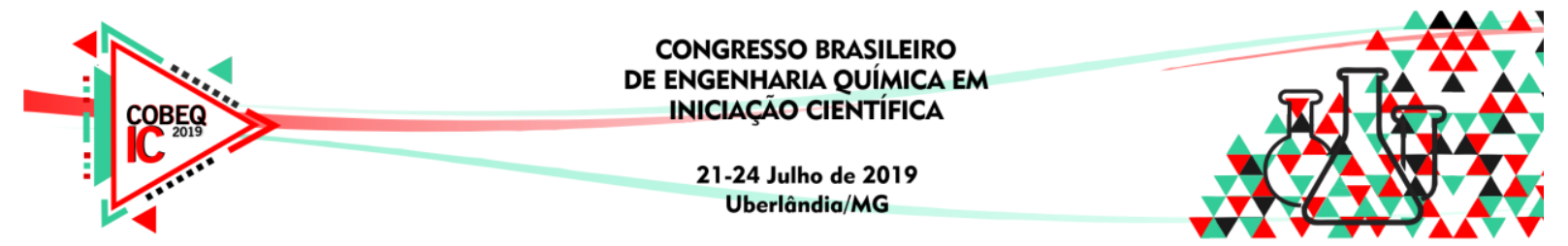

\section{RESULTADOS E DISCUSSÃO}

\subsection{Adsorção do glicerol livre}

Os testes preliminares foram realizados a fim de determinar a quantidade ideal de adsorvente adicionado ao biodiesel que promovesse uma melhor adsorção. Utilizando a equação da reta obtida pela curva padrão foi possível quantificar o teor de glicerol nas amostras adsorvidas pelo amido de milho. Os valores obtidos podem ser encontrados na tabela 1 .

Tabela 1: Concentração e porcentagem de remoção das amostras adsorvidas.

\begin{tabular}{|c|c|c|}
\hline Amostras de biodiesel & Concentração (mg/mL) & \% Remoção \\
\hline Puro* & 0,00843 & - \\
\hline Lavado com água & 0,00641 & 23,96 \\
\hline Amido de milho 1\% & 0,00367 & 56,46 \\
\hline Amido de milho 2\% & 0,00148 & 82,44 \\
\hline Amido de milho 3\% & 0,00141 & 83,27 \\
\hline
\end{tabular}

*Puro = biodiesel obtido logo após decantação do glicerol bruto.

Com base nos dados da Tabela 1, verificou-se que o melhor resultado obtido foi utilizando a adsorção com amido de milho em $3 \%$ da massa total de biodiesel, em que se observou que a concentração final de glicerol livre foi de $0,00141 \mathrm{mg} / \mathrm{mL}$, totalizando uma remoção de 83,27\% em relação ao biodiesel puro. Esses resultados demonstram a eficácia da remoção do glicerol residual por adsorvente sólido, sem a necessidade da realização de lavagens consecutivas com água. Além da geração de grandes volumes de água contendo glicerina e catalisador homogêneo, a lavagem com água demonstrou ser menos eficaz na remoção do glicerol, visto que removeu apenas $23,96 \%$. A análise cromatográfica indicou que a porcentagem residual de glicerol livre na amostra de biodiesel após adsorção com $3 \%$ de amido milho foi de $0,05 \%$, comprovando a eficiência da remoção do glicerol.

\subsection{Caracterização do biodiesel obtido}

A fim de determinar se o biodiesel obtido antes e após o processo de adsorção atendeu as especificações da ANP, o produto foi submetido a uma série de análises físico-químicas que atestam sua qualidade. A Tabela 2 descreve os valores obtidos antes e após o processo de adsorção com $3 \%$ de amido de milho.

Os dados da Tabela 2 indicam que tanto o biodiesel puro quanto o biodiesel após o processo de adsorção apresentaram resultados dentro dos valores estabelecidos pelas normas da ANP, com relação à viscosidade cinemática, densidade e o índice de acidez, indicando assim que o processo e adsorção não afetou a qualidade do biodiesel final. Quanto ao teor de glicerol livre somente o biodiesel após adsorção apresentou valor abaixo do valor predito pela norma, indicando que o adsorvente foi capaz de remover uma quantidade ideal de glicerol livre. 


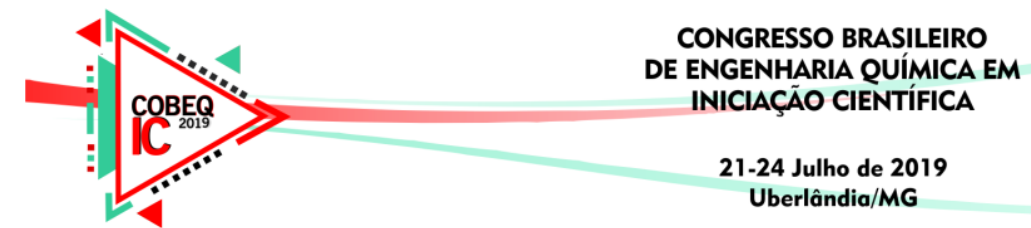

O rendimento em ésteres metílicos em porcentagem mássica foi determinado por análise cromatográfico e foi constatado que o biodiesel obtido apresentou um valor de $97 \%$ de rendimento. Os teores de mono-, di- e triglicerídeos foram de 0,67\%, 0,90\% e 1,55\% respectivamente, demonstrando a eficiência da produção do biodiesel.

Tabela 2: Caracterização do biodiesel antes e após o processo de adsorção.

\begin{tabular}{|c|c|c|c|}
\hline Parâmetros & Biodiesel Puro & $\begin{array}{c}\text { Biodiesel adsorvido } \\
\text { (Amido de milho 3\%) }\end{array}$ & $\begin{array}{c}\text { Especificações da } \\
\text { ANP (2014) }\end{array}$ \\
\hline \hline $\begin{array}{c}\text { Densidade a } 20^{\circ} \mathrm{C} \\
\left(\mathrm{Kg} / \mathrm{m}^{3}\right)\end{array}$ & 885,75 & 878,96 & $850-900$ \\
\hline $\begin{array}{c}\text { Viscosidade absoluta a } 40^{\circ} \mathrm{C} \\
\left(\mathrm{mm}^{2} / \mathrm{s}\right)\end{array}$ & 4,74 & 4,70 & - \\
\hline $\begin{array}{c}\text { Viscosidade cinemática } \\
(\mathrm{cSt})\end{array}$ & 5,35 & 5,35 & $3-6$ \\
\hline $\begin{array}{c}\text { Índice de Acidez } \\
(\mathrm{mg} \mathrm{KOH} / \mathrm{g})\end{array}$ & 0,1669 & 0,2289 & $\begin{array}{c}\text { Até 0,5 mg KOH/g } \\
\text { de óleo }\end{array}$ \\
\hline $\begin{array}{c}\text { Concentração de Glicerol livre } \\
(\mathrm{mg} / \mathrm{mL})\end{array}$ & 0,008 & 0,0014 & Até 0,002 \\
\hline
\end{tabular}

\section{CONCLUSÕES}

Com base nos resultados apresentados, é possível concluir que o amido de milho foi eficaz na purificação por adsorção do biodiesel, uma vez que se pode observar que os valores da concentração de glicerol livre diminuíram significativamente nas amostras adsorvidas. Dessa forma o trabalho apresentou uma alternativa ambientalmente favorável aos métodos tradicionais existentes, sendo necessário mais estudos a fim de otimizar as condições do processo, viabilizando sua aplicação comercial.

\section{AGRADECIMENTOS}

Os autores agradecem o suporte financeiro concedido pela FAPEMIG.

\section{REFERÊNCIAS BIBLIOGRÁFICAS}

ANP - Agência Nacional de Petróleo, Gás Natural e Biocombustíveis. Resolução $n^{\circ} 45$, de 25.8.2014-DOU 26.8.2014.

AOCS American Oil Chemists Society Official Methods and Recommended Practices of the AOCS. $5^{\text {th }}$ Ed. AOCS Press 2004.

DABDOUB, M. J. REIS, G. N. R.; LOPES, A.; FURLANI, C. E. A.; SILVA, R. P.; GROTTA, D. C. C.; CAMARA, F. T. Análise comparativa entre biodiesel filtrado e biodiesel destilado em tratoragrícola. Revista de Ciências Agroveterinárias, v.5, n.2, p.149-155, Lages, 2006.

INSTITUTO ADOLFO LUTZ. Métodos Fisicos-Quimicos para análises de alimentos.São Paulo: Instituto Adolfo Lutz, 2008. 


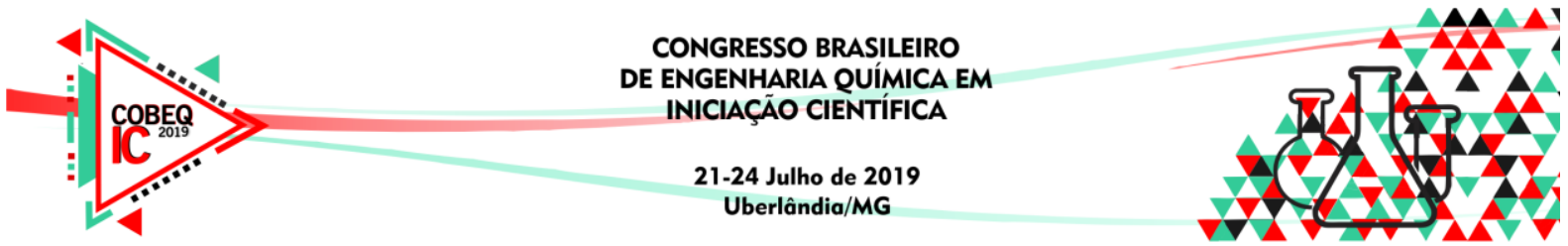

LOPES, A. N.; CECHINEL, C. A.; WENTZ, A. P. Co-Produto do biodiesel- novas aplicações para glicerina. Diálogos \& Ciência. Revista da Faculdade de Tecnologia e Ciências, 2011.

MEHER, L.C. SAGAR, D.V. e NAIK, S.N. Technical aspects of biodiesel production by transesrification - a review. Renewable and Sustainable Energy Reviews, v. 10, n. 3, p. 248-268, 2006. 